Es wird heute kaum mehr bestritten, daß der Energiethematik in der Umweltdebatte eine Schlüsselrolle zukommt und die unnötige Verschwendung von zu billiger Energie die Wurzel vieler Übel darstellt (Luftverschmutzung, Klimaveränderungen, radioaktive Abfälle und anderes mehr). Die Geister scheiden sich bei der Frage, wie, wann und wie rasch diese fatale Energieabhängigkeit gemildert werden kann. Der hier vorgeschlagene Weg zur nachhaltigen Energiewirtschaft geht nicht, wie die meisten aktuellen Vorschläge, vom Energiepreis aus, sondern von der absoluten Höhe des Energieangebots. Das Konzept "Energieschranke", bereits vorgestellt im Editorial der dritten Ausgabe von GAIA 1992, faßt das Ziel der Verminderung gesellschaftlicher Energieabhängigkeit direkt ins Auge, es bedarf dazu nicht einer Energiesteuer. Tatsächlich ist Energie nicht das einzige Gut, dessen Angebot - künstlich oder natürlich - begrenzt ist, denken wir nur an das mancherorts limitierte Bauland. Und da es sich eine Volkswirtschaft auf die Dauer kaum leisten kann, immer knapp an der obersten erlaubten Energiegrenze herumzuschwanken, dürfte der Markt durch Innovationen dafür sorgen, daß er sich als Folge einer intelligenten Energienutzung von der gefährlichen oberen Schranke entfernt. Wie erste Erfahrungen mit sogenannten Umweltbelastungs-Zertifikaten zeigen, darf mit gutem Grund spekuliert werden, daß eine Energieschranke schließlich zu einer Verminderung der Energiedegradierung führen würde - und dies nicht notwendigerweise bei höheren Energiepreisen.

\title{
The
}

\section{Energy Needs of Today are the}

\section{Prejudices of Tomorrow"}

\author{
Dieter M. Imboden*
}

Abstract: Sustainable development in its literal meaning as a strategy which depends on renewable resources cannot be attained for the present global energy needs. A more realistic goal, the concept of constant time of safe practice, is proposed according to which the time into the future should not decrease during which the actual strategy of development (as given by the overall policy regarding population growth, energy, economy, land use, et cetera) can be guaranteed - to the best of our knowledge - as being safe and sustainable. Since every mode of energy supply, whether from renewable sources or not, limits the society's option to some extent, it is proposed to put an absolute limit to the level of energy use.

The principle of energy bounds is meant as an alternative to the method of energy taxation.

*Postal address : Prof. Dr. D.M. Imboden Swiss Federal Institute for Environmental Science and Technology (EAWAG)

and Swiss Federal Institute of Technology (ETH) CH-8600 Dübendorf (Schweiz)
The former addresses directly the ultimate goal to reduce our energy dependence while the latter, due to adjustment of the energy needs to the new prices, may not be the adequate tool to bring about, in the long run, a smaller rate of energy degradation.

Keywords: constant time of safe practice, energy, energy bounds, error friendliness, sustainability, technology assessment

\section{Today's Global Energy Situation}

Energy in combination with technological innovation has played a key role in the formation of modern society in which - as we are inclined to believe - hunger and poverty have become a mere problem of the just distribution of goods and wealth. As never before in its history, mankind depends on the availability of cheap energy. Today, the major portion of this energy is supplied 2) by nonrenewable resources such as fossil and nuclear fuels. Part of the renewable energy resources are exploited at a rate which exceeds their capacity of recovery (wood).

As shown in Table 1, the global commercial energy supply in the year 1989 was $311 \times 10^{18}$ joules, that is on the average 10 terawatts $\left(10 \times 10^{12}\right.$ joules per second). This figure does not include the energy acquired from non-commercial resources such as firewood or animal waste collected by the consumer. About 95 per cent $(\%)$ of the commercial energy is based on fossil fuels; the rest (5\%) is provided as primary electricity not produced by burning of fossil fuels. Nearly all this non-fossil electricity originates either from hydropower or nuclear power. The new technologies (geothermal, solar, wind) play only a minor role, at least on a global scale.

In spite of the enduring discussion on the negative aspects of the world's growing energy demand, the situation has only slightly changed in the last ten to twenty years, except for the fact that supply increased less during the last ten years (14\%) than during the ten preceding years $(32 \%)$. The $14 \%$ growth rate since 1979 represents the combined effect of a $60 \%$ increase in primary electricity and a below-average growth rate $(12 \%)$ of fossil fuels. Yet, if expressed in absolute terms by far the largest addition to the energy supply was based on coal and natural gas (mineral oil underwent a small decrease). The largest absolute increase to the non-fossil production of electricity is due to nuclear power, though the relative contribution of nuclear energy to total energy supply is only a little over $2 \%$.

The one-sided dependence of our society on fossil fuels is paralleled by a salient imbalance in the geographical distribution of energy degradation. As exemplified in Table 2 by a few selected nations, the per capita energy requirement varies from well below 300 watts (for example, many African and Asian states) to well above 10000 watts (for

\footnotetext{
1) Elaborated version of an invited lecture, presented at the International Colloquium "Energy Needs in the Year 2000 and Beyond: Ethical and Environmental Perspectives" in Montreal, Canada (May 13-14, 1993).

2) We are accustomed to use expressions such as "energy production" and "energy consumption". As explained in Excursus I in this article, these terms are replaced by

"energy supply" and "energy degradation".
} 
Table 1. Commercial Energy Supply (1989). a

\begin{tabular}{|c|c|c|c|c|}
\hline & & \multicolumn{2}{|l|}{$10^{18}$ joules $^{b)}$} & Change since 1979 (\%) \\
\hline \multicolumn{2}{|c|}{ Total (world) } & 311.0 & & $+14^{c)}$ \\
\hline Fossil & $\begin{array}{l}\text { Solid } \\
\text { Liquid } \\
\text { Gas }\end{array}$ & $\begin{array}{r}95.7 \\
130.3 \\
70.5\end{array}$ & & $\begin{array}{l}+26 \\
-\quad 4 \\
+33\end{array}$ \\
\hline \multicolumn{2}{|c|}{ Total Fossil } & & $\begin{array}{c}296.5 \\
\text { (95\% of total) }\end{array}$ & +12 \\
\hline \multicolumn{2}{|c|}{$\begin{array}{l}\text { Primary Electricity } \\
\text { Geothermal \& Wind } \\
\text { Hydro } \\
\text { Nuclear }\end{array}$} & $\begin{array}{l}0.14 \\
7.5 \\
6.8\end{array}$ & & $\begin{array}{l}+244 \\
+33 \\
+201\end{array}$ \\
\hline \multicolumn{2}{|c|}{ Total Primary Electricity } & & $\begin{array}{c}14.5 \\
\text { (5\% of total) }\end{array}$ & +60 \\
\hline
\end{tabular}

a) Data from World Resources 1992/93 [1]. Supply from fossil fuels is calculated based on the average specific energy content of each of the three categories, solid, liquid, and gas The figures include the fossil fuels which are burnt to produce electricity. The figures for primary electricity correspond to the total electric energy production of all hydroelectric, nuclear and other (non-fossil fuel) plants. It does not account for the waste heat which results from the production of electricity from heat (see Excursus I).

b) $10^{18}$ joules $=1$ million terajoules $=1$ million million megajoules

c) During the last 20 years, global energy supply increased by $50 \%$.

Table 2. Energy Degradation (1989). a)

\begin{tabular}{lccccc}
\hline & $\begin{array}{c}\text { Total } \\
\left(10^{18} \text { joules }\right)\end{array}$ & $\begin{array}{c}\text { Change } \\
\text { since 1979 } \\
(\%)\end{array}$ & $\begin{array}{c}\text { Per } \\
\text { capita } \\
\text { (watts })\end{array}$ & $\begin{array}{c}\text { Change } \\
\text { since 1979 } \\
(\%)\end{array}$ & $\begin{array}{c}\text { Non- } \\
\text { commercial b) } \\
\text { (\% of total) }\end{array}$ \\
\hline World & $347^{\mathrm{c})}$ & +22 & 2100 & +2 & 6 \\
Africa & 12.4 & +42 & 630 & 6 & 37 \\
\multicolumn{1}{c}{ Zaire } & 0.42 & +31 & 380 & -3 & 76 \\
Asia & 84 & +52 & 900 & +26 & 10 \\
$\quad$ Sri Lanka & 0.15 & +21 & 290 & +5 & 52 \\
$\quad$ Chdia & 10.7 & +70 & 410 & +37 & 25 \\
China & 28.8 & +58 & 820 & +38 & 6 \\
Europe & 74.4 & +6 & 4600 & +2 & 1 \\
USA & 80.6 & +6 & 10300 & -4 & 2 \\
Canada & 11.1 & +20 & 13400 & +9 & 1 \\
\hline
\end{tabular}

a) Data from World Resources 1992/93 [1] (see Excursus II for definitions of energy units).

b) Traditional fuels such as firewood, animal waste, et cetera.

c) Note that in 1989 total energy degradation was larger than total commercial energy supply (confer Table 1). This is due to changing stocks of fuels and the contribution of non-commercial fuels.

example, USA, Canada). The largest growth rates of (total and per capita) energy degradation are found in states with below-average per capita needs (for example, China, India), but not in the "energy-poorest" countries (for example, Zaire, Sri Lanka) where in some cases per capita degradation has even dropped during the last 10 years. In these countries, traditional (non-commercial) energy sources provide more than half of the energy needs. ed. Among the truly renewable resources only solar energy, exploited either directly (for instance, as thermal energy, electricity by photovoltaic cells, et cetera) or via the use of biomass and hydropower, would have the potential to match today's global energy needs. As listed in Table 3, the total solar energy input to the climate system of the earth (122000 terawatts) is about 12000 times greater than today's total commercial energy supply (10 terawatts). The yearly global biological gross primary production amounts to about 130 terawatts and is roughly equally distributed between the marine and terrestrial ecosystems. This means, on one hand, that the global biological system extracts and stores (by photosynthesis) only about $0.14 \%$ of the solar energy flux. On the other hand, the commercial energy flux has reached nearly $8 \%$ of gross biomass production, and in some densely populated areas even has surpassed it if the anthropogenic flux is related to the corresponding area.

The demand of the human population for food (physiological energy demand), calculated as 10000 kilojoules per capita and day for 5.3 billion $\left(10^{9}\right)$ people, amounts to 0.6 terawatts. Since in the present agricultural system the conversion of biological primary production to food energy is far below $100 \%$ and requires the additional degradation of fossil energy (mechanical energy for cultivation, production of fertilizers, and so on), the real energy demand for food production must be significantly larger. In addition, a considerable portion of food, especially in the rich countries, is not consumed as plants (corn, fruit, vegetable, et cetera) but as meat for which seven to ten times more primary plant energy is needed to produce a given amount of food energy. Thus, all these points combined lead to the conclusion that in fact more than $10 \%$ of the landbased global primary production is occupied by man for his food requirements. This food is primarily produced on crop land which amounts to only about $10 \%$ of the total area of the continents.

The transition to a solar-based energy system, if really feasible at the present level of energy demand, would not be trivial, neither technically nor economically and politically. If this energy were to be provided by biomass (biofuel), a severe competition between food and fuel production would be inevitable. If it were possible to extract, on the average, 5 watts per square meter as biofuel (corresponding to $44 \mathrm{kWh}$ per $\mathrm{m}^{2}$ and year), today's total energy demand would require more than $13 \%$ of the world's 
crop land (see Table 3). This figure is rather optimistic and would put enormous pressure on the agricultural structures of many developing countries which are

often located in those areas most suitable for the production of biofuel. These nations would then be caught between the necessity to feed their people and the

Table 3. Global Solar Energy Fluxes.

terawatts

Total short-wave solar radiation at surface of earth per area total

240.00 watts per square meter

Commercial energy supply
per area

Commercial energy supp
per area

total

0.02 watts per square meter

ical energy demand

Human physiological energy
per capita

total

100 watts per capita

primary production

total

on land

Gross primary production on land related to

$\begin{array}{ll}\text { area of total land } & 0.44 \text { watts per square meter } \\ \text { area of usable land } & 0.73 \text { watts per square meter } \\ \text { area of crop land } & 4.30 \text { watts per square meter }\end{array}$

Percentage of crop land needed to produce total commercial energy needs

(based on gross production of 5 watts per square meter): $13.3 \%$

\section{Excursus I: Can Energy be Produced and Consumed?}

The term "energy production" frequently used even by the specialist, is self-contradictory. According to the first law of thermodynamics energy can neither be produced nor destroyed; it can only be transferred and transformed from one form (for example, from the energy of motion called kinetic energy) into another form (for example, into thermal energy as measured by temperature). In fact, the law of energy conservation has been one of the corner-stones of classical physics - and it still is in today's physics, although the theory of special relativity by Einstein has led to an extension of the law by introducing the equivalence of mass and the classical energy forms, so powerfully demonstrated by the energy set free by nuclear reactions.

In spite of its central meaning it is not easy to adequately define the term "energy". Energy is involved wherever changes occur. Thus, energy could be defined as the necessary ingredient, that is the capacity, for change. However, our experience in daily life tells us that the capacity for change is not identical with the potential for change. For instance, if we want to heat the interior of a house to $20^{\circ} \mathrm{C}$ we cannot fully extract the energy contained in the drinking water available at the water-tap at a temperature of $12^{\circ} \mathrm{C}$ - in spite of the huge thermal energy contained in every liter of this water. In contrast, the energy from the electric wall-socket does not pose any problems for our heating needs

The lesson from this example is the following: Energy comes in various forms of different qualities. Energy of high quality can easily and completely be transformed into energy of lower quality. Electricity and mechanical energy (energy contained in the movement or height of masses) have the highest quality. The quality of thermal energy is smaller; it decreases with decreasing temperature at which the thermal energy is provided.

The transformation of energy from lower to higher quality is only partially possible. The maximum transfer rate, called efficiency, is limited by a basic law of thermodynamics (the law of thermodynamic efficiency by Carnot). According to this law, in a thermal electric power station only 30 to $40 \%$ of the energy extracted from the fuel (fossil or nuclear) can be transformed into electricity; the remaining energy is "dumped" into the environment (atmosphere, river, ocean) as so-called waste heat.

In fact, "energy production" and "energy consumption" are unprecise expressions for the "supply of energy of high quality" and for its transformation into energy of lower quality by the "consumption" process; the latter is more adequately called "energy degradation". temptation to produce fuel for export to the rich countries. Furthermore, via the extensive use of fertilizers and pesticides a highly efficient biofuel industry would inevitably put additional stress on terrestrial and aquatic ecosystems and thus on biodiversity.

As an alternative, large solar power plants could be constructed on arid land which cannot be used for food production. Yet, the supply, storage and distribution of such quantities of energy need a gigantic apparatus which, in many ways, may be socially incompatible and vulnerable. The lesson to be learnt from these considerations is that at the present level of global energy demand it is not relevant whether this energy comes from a fossil, nuclear or solar source; all modes of supply require a sophisticated level of technical and economic organization.

The mentioned reservation regarding the possible role which solar energy could play in the global energy scenario needs a supplementary remark: For countries with below-average per capita energy degradation, especially if located in the low latitudes where solar radiation does not vary much during the year, solar energy, either exploited by photovoltaic techniques or thermally, can be of major importance as a supplement or substitute for the traditional non-commercial energy resources. For instance, in many countries collection of firewood for cooking binds a large fraction of the available time of some family members (usually women or children). Simple solar stoves can be a significant relief for their daily life. In contrast, in societies with a per capita energy degradation of 4000 watts or more it is much more difficult to turn solar power into an energy source of significant relative importance. Thus, although solar energy could become important for a large fraction of the human population, we are still far away from the point where it could substitute a significant part of today's total energy demand.

\section{Sustainable Development and the Concept of Constant Safe Practice}

While new technologies, such as the development of solar energy, could significantly change the energy situation of countries with low per capita energy demand indeed, such a drastic change is much harder to attain in industrialized countries. I strongly believe that neither technology nor the forces of the free mar- 
ket in their present form can take account of all the prejudices which are inherent in our present energy system. I shall elaborate on this view with the help of five theses.

Thesis 1: Based on our present knowledge it is difficult to imagine how, for today's global energy needs, sustainable development in its literal meaning (as the policy of development which only depends on renewable resources and thus could be continued for ever) can be attained.

As an alternative interpretation of sustainability I propose to use a new concept which I call the concept of constant time of safe practice. This concept is based on the analysis of the actual strategy of development of a nation (or a continent or the whole world), that is on the policy regarding such vital factors as economy, energy supply, population growth, land use, et cetera. We all know that a nonzero population growth, the exploitation of non-renewable resources and so on cannot be pursued for ever, but we are used to set our mind at rest by estimating the time during which our present policy (or practice) can be sustained without severe problems. The principle of constant time of safe practice expresses the condition that this time should not decrease over time, that is that the development of alternative strategies and new resources should, at least, keep pace with the exploitation of our reserves of land and resources.

This concept is indeed not meant as an incitement to shift our present problems to the next generations by exploiting all remaining capacity which separates the actual situation from the borderline to disaster. Let us assume that a simple model predicts that, as a consequence of the use of sewage sludge to fertilize cultivable land, the concentration of some heavy metal in the soil increases by $4 \%$ per year of the tolerance concentration. It would be fatal to conclude that the time of safe practice is 25 years. In fact, safe practice should leave the environment still essentially untouched at the end of the period which has been found to be safe for this practice. - In contrast, it would be safe to use the fertilizing techniques as a provisional measure if after the period of application the total increase of the relevant concentrations would still be much smaller than the tolerance limit - and small compared to

\section{Excursus II: Energy and Power}

The basic unit of energy in the International System of Units (SI) is the joule (J). With 10 joules we can raise 1 liter of water by about 1 meter or increase its temperature by just a little more than two thousandths of a degree Celsius. This demonstrates our different perception of mechanical energy (raising masses) versus thermal energy (changing temperatures). The size of energy supply facilities can be measured by their maximum energy output per unit time, that is by their maximum power output. Power is energy per unit time. It is measured by the unit watt $(\mathrm{W}): 1$ watt is equal to 1 joule per second.

For the non-expert it may be confusing that electric power companies use the unit kilowatt-hour (kWh) to charge for their services. A kilowatt-hour is an energy, not a power unit (power times time); it measures, for instance, the integral energy output of a power source of 1000 watts during one hour, or of a power source of 3600000 watts (3.6 megawatts $=3.6 \mathrm{MW}$ ) during one second, or of a power source of 0.114 watts during the 8760 hours of one year. The following relation is helpful: An energy supply of $1 \mathrm{kWh}$ per year corresponds to an average power output of 0.114 watts.

A reliable thermal power plant (fossil or nuclear) can operate at its maximum power output during 80 to $90 \%$ of the year (availability); the rest of the year is required for services and repair. Thus, a plant with an electric power output of $1000 \mathrm{MW}$ and an availability of $90 \%$ produces about 7900 million kWh every year. In contrast, the yearly energy supply of most hydroelectric plants is not limited by the maximum installed power output, but by the available water to operate the turbines. Thus, the capacity of hydropower stations is often given by the amount of kilowatt-hours produced during the average hydrological year. By using the above relation one can calculate an average power output. Commonly, this number is significantly smaller than the maximum installed power. For instance, the energy output of a $100 \mathrm{MW}$ plant may typically be 400 million kWh per year corresponding to an average power output of about $45 \mathrm{MW}$.

In order to compare continuous energy fluxes (such as the energy output of thermal power plants or of the sun) to time-variable energy fluxes (for example, the energy output of hydroelectric power plants or the energy demand of individual households), all energy fluxes per unit time listed in Tables 2 and 3 are expressed by the basic power unit of watts.

the natural concentration fluctuations in this area.

On one hand, the principle of constant time of safe practice is less restrictive than sustainability in its literal sense since it still allows to use non-renewable resources, at least as long as innovations (technical and others), which are relevant for extending the use of these resources, are developed faster than the latter are consumed. For instance, the exploitation of some rare elements, such as wolfram (tungsten), which are vital for certain present technologies, such as the production of a special kind of steel, may be in accordance with the principle of constant safe practice if material sciences is capable to develop alternatives for such "classic" materials. On the other hand, the principle of constant safe practice may be more restrictive by putting some limits to the use even of renewable (for example, solar) or quasi-unlimited resources (for example, nuclear). For instance, the large areas of land needed if solar energy is to become a major energy source, or the extensive production of nuclear waste in case of a significant increase of nuclear energy supply, may both cause a significant reduction of the time of safe practice due to growing social pressure and unrest being built up against these technologies.

\section{Technology Assessment}

The planning and managing of our future is still dominated by the engineer's approach which - for the tasks for which it was developed - has been extremely successful. The engineer was taught to design machines, to construct buildings, bridges, et cetera. He bases his approach on the "laws" of natural sciences, on physics and chemistry. These fundamentals have been shaped by a long tradition of comparing observational with theoretical knowledge. They have reached a level of certainty which makes it highly unlikely that, for instance, the law of statics may suddenly change in such a way to make bridges collapse.

Of course, engineers have often failed and will continue to do so. They may overlook certain properties of complex structures, synergetic effects arising from the combination of factors which, if analyzed separately, are well understood. 
However, every failure of this kind has led to the corresponding refinement of the engineer's practice. Therefore, we usually put a considerable trust in the proper performance of machines which were designed long ago.

The concept of "technology assessment" is the answer of modern society to its often painful experience that the possible weaknesses and long-term consequences of complex technologies require a more advanced process of learning. The concept is both a necessary step to cope with the many inadvertent consequences of modern technologies, and a dangerous fallacy which makes us believe that the engineer's approach will eventually provide us with the "social laws" needed to avoid the undesirable consequences of these technologies. Meanwhile we all know that it is by far easier to build a technically safe (or at least nearly safe) power plant than to fancy about the kind of weird situations which the "human factor" will be able to produce in such a plant. It is not astonishing that engineers more and more tend to exclude the human factor from their design. However, this will not solve the dilemma since these designs again depend on the human factor. Man cannot hand over all his responsibility to the machines. Applied to the energy problem this leads to the next thesis:

Thesis 2: The time of safe practice depends not only on limitations of physical resources but also on the social compatibility of new technologies. Our experience in the past should have taught us that part of the social costs are unpredictable and delayed.

Thus, even the best technology assessment leaves us with certain risks and with prejudices for the future which, since they are unknown, cannot be included into the price in a rational manner.

Thus, qualitatively spoken, if the complexity of a new technology exceeds a certain level, it tends to reduce the time of safe practice.

Today's energy requirements have reached a level which is comparable to the size of energy fluxes within the global ecosystem (Table 3). Although the use of the immense solar energy flux to which the earth is exposed can and should be further developed, the present temporal and geographical distribution of society's energy demand would require a highly advanced system for production, storage and distribution, if solar energy is to take over a significant portion of the global energy supply. The necessary techniques, such as the construction of large photovoltaic power plants and the development of energy storage systems, for example, on the basis of hydrogen, create a new kind of long-term boundary condition and perseverance.

\section{The Principle of Error Friendliness}

Given the immanent limitations of even the best technology assessment, the main guide-line of our future technological innovations should be the principle of error friendliness, by which is meant the design of systems which can easily be adjusted to new experience and better ideas. ${ }^{3)}$ For instance, a device in which energy is obtained by biogas from the locally grown biomass is easier to adjust to new needs and yet unknown ecological side-effects than a network of centralized energy production plants combined with a sophisticated system of distribution and storage.

For the same reason that a driver has to slow down his car in order to adjust his braking distance to a reduced range of sight, our present unpredictability of ecological, climatic, and socio-political factors makes it necessary to guarantee the needed time of safe practice by reducing the level of energy dependence.

3) This principle belongs to the "seven criteria for technology development" which have been proposed by Ernst U. von Weizsäcker in his book Erdpolitik ${ }^{[2]}$

4) The data set given by Rudolf Rechsteiner [3] supports this view.

Traditional, "low tech" but renewable, non-commercial energy resources: In quite many regions collection of firewood for cooking takes up a large part of the available time of some family members - usually women or children. Photo: Dr. Verena Keck, Ethnologisches Seminar, Universität Basel.

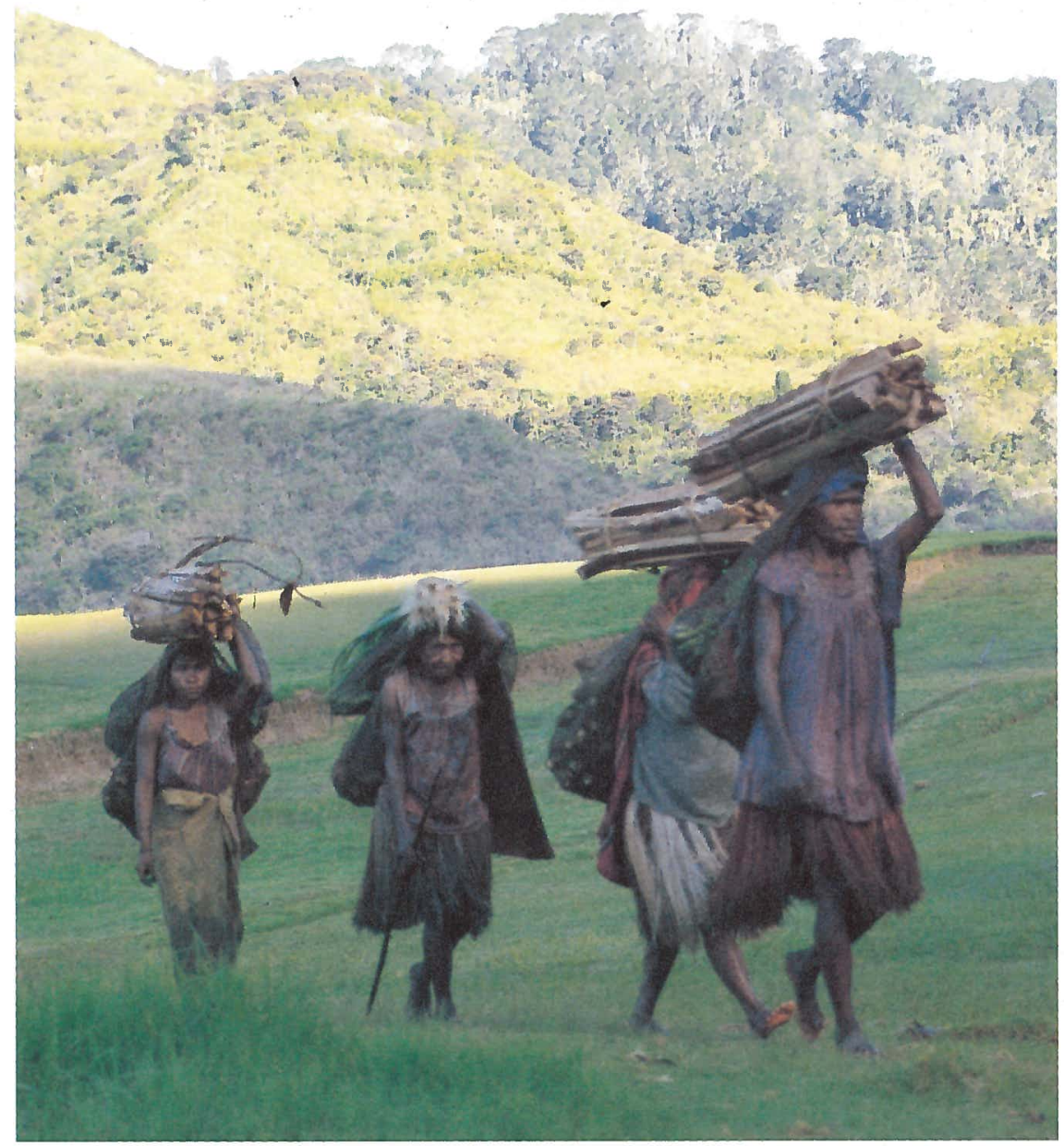


Thesis 3: Since every mode of energy "production", if applied at large, limits society's future options to some extent, the time of safe practice must be inversely related to the level of energy requirement.

This applies independently on how this energy is supplied.

\section{Market Forces and Energy Bounds}

Many economists and politicians believe that the forces of the free market are capable in their present form to induce the necessary transition from the "bad" to the "good" energy resources if only the prices reflect the real costs of energy supply. The internalization of all external costs, that is the price of "free" goods like clean air, uncontaminated water, silence, or the beauty of a landscape, is rightly to be considered as the most important mechanism to transform the laws of the free market into an ecologically sound system. The confidence in this mechanism rests on the assumption that there exists a unique relationship between the price of a commodity and its demand. If the demand should be reduced, the price has to be increased by an amount which can be calculated from the local slope of the price/demand curve, that is by the so-called elasticity (Figure 1).

Yet, there are serious doubts whether this economic model is suitable as the sole instrument to limit energy degradation on a national or even global level. In fact, the model does only relate changes of prices with changes of demands, but not the absolute level of energy demand to an absolute level of energy price. In the industrialized countries the energy price is much less decisive for the price of the final product than the price of labor (perhaps with the exception of a few energy-intensive goods such as aluminium). ${ }^{4)}$ Therefore, in the long run the energy price cannot be the dominant factor to control the energy "consumption". If we are convinced that from the point of view of a constant time of safe practice the absolute level of energy degradation should be limited, one has to rely either on a feedback mechanism in which the energy price is continuously adjusted to the changing demand, or on an additional concept, the concept of energy bounds. The former creates an uncertain milieu for the long-term economic planning process, a disadvantage which for the latter approach can be avoided.

Thesis 4: The concept of constant time of safe practice can only be attained

by putting an absolute limit to the level of energy use.

Though changes in the exploitation of the different energy resources may temporarily improve the sustainability of our life-style, they cannot really solve the dilemma between the time of safe practice and the growing energy demand.

The energy needs of today are the prejudices of tomorrow.

The concept of energy bounds has recently been proposed by Imboden, Jaeger, and Müller-Herold ${ }^{[4]}$. In contrast to the concept in which the price struc-

Modern, "high tech" but non-renewable, commercial energy resources: chiefly the relatively cheap fossil and nuclear fuels.

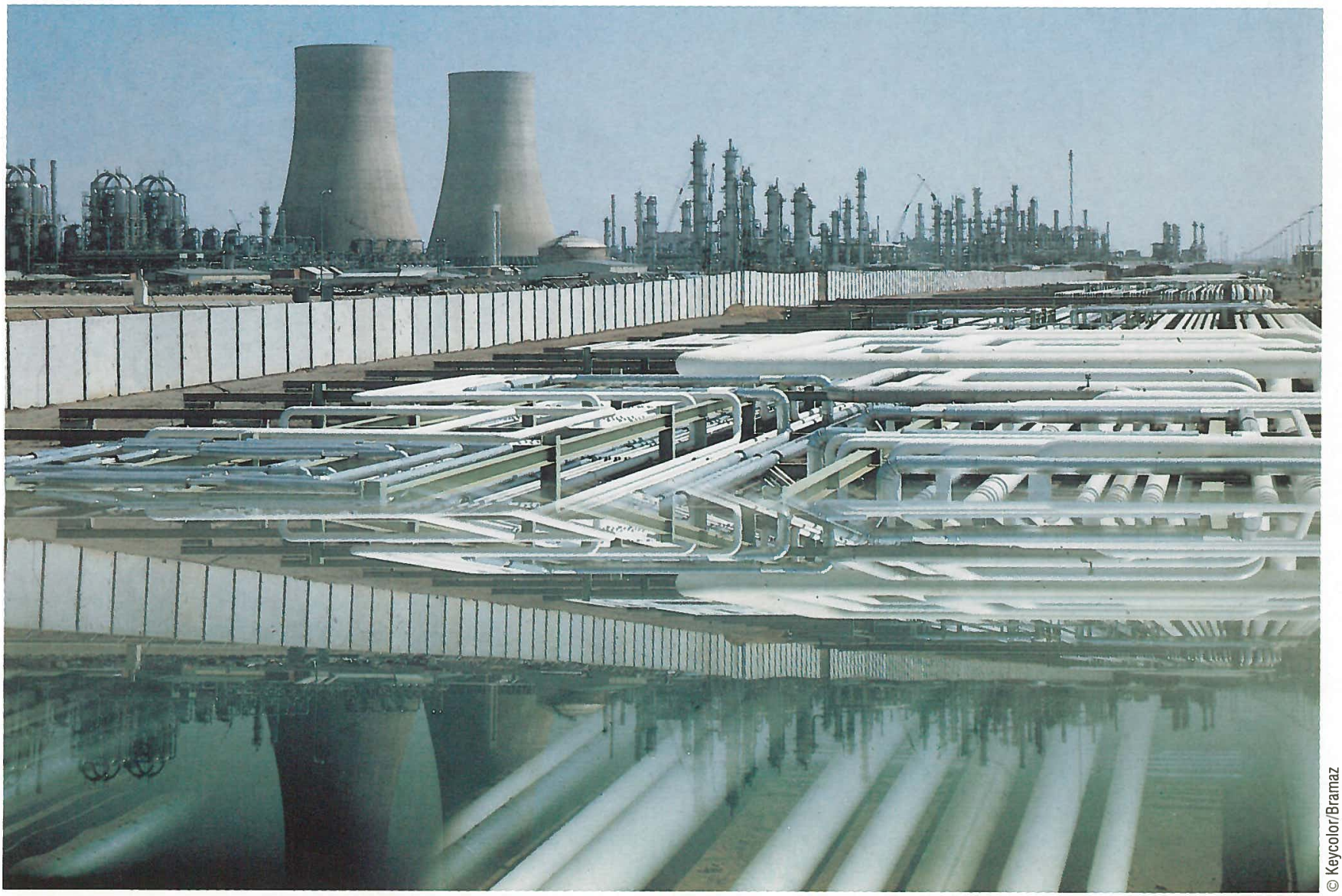


ture is the controlling parameter, the concept of energy bounds uses the energy supply as the ultimate goal function while the price is a free variable which adjusted itself according to the ratio between demand and supply. There exist numerous examples where historically given market forces alone were not considered as sufficient to reach a certain goal. For instance, after a series of catastrophes such as frequent flooding of alpine valleys and the destruction of human settlements by snow avalanches, in the second half of the 19th century the Swiss realized that deforestation in their country should come to an absolute halt. The Swiss law of forestry which became effective in 1902 requires, that the area covered by forest shall remain constant. Thus, whenever part of a forest has to be cut, like for the construction of a new road, an area of at least equal size has to be transformed into a new forest. As another example, some countries limit the land area to be used for settlements. The real estate market demonstrates that the rules of the free market can be adjusted in order to cope with the distribution of a good with limited supply.

In fact, society is confronted with absolute limits of even stronger urgency, for instance regarding the preservation of biodiversity. Since biological extinction is a truly irreversible process, no market should have the right to pay whatever price to erase a species.

Energy and economic development are, in fact, decoupled to a large extent ${ }^{[3]}$. The example of Japan which has increased its energy price and which today has a ratio between gross national product (GNP) and energy degradation which is three times lower than that of the USA (and four times lower than that of Canada) demonstrates that a country which deliberately restricts its use of energy may not only get away without too much problems but may even emerge stronger and more competitive, especially since sooner or later others may have cut down their energy needs as well. There is a tremendous market out there for energy-efficient technologies, and this market will hardly be conquered by those who still can waste energy at home!

There are various possibilities to implement the concept of energy bounds. For instance, initiatives could first be taken by individual countries by introducing into their constitution an amendment in which the use of commercial energy is absolutely limited. It would also be possible to introduce the energy bounds stepwise by defining limits which decrease in time until the final sustainable level of commercial energy use is reached.

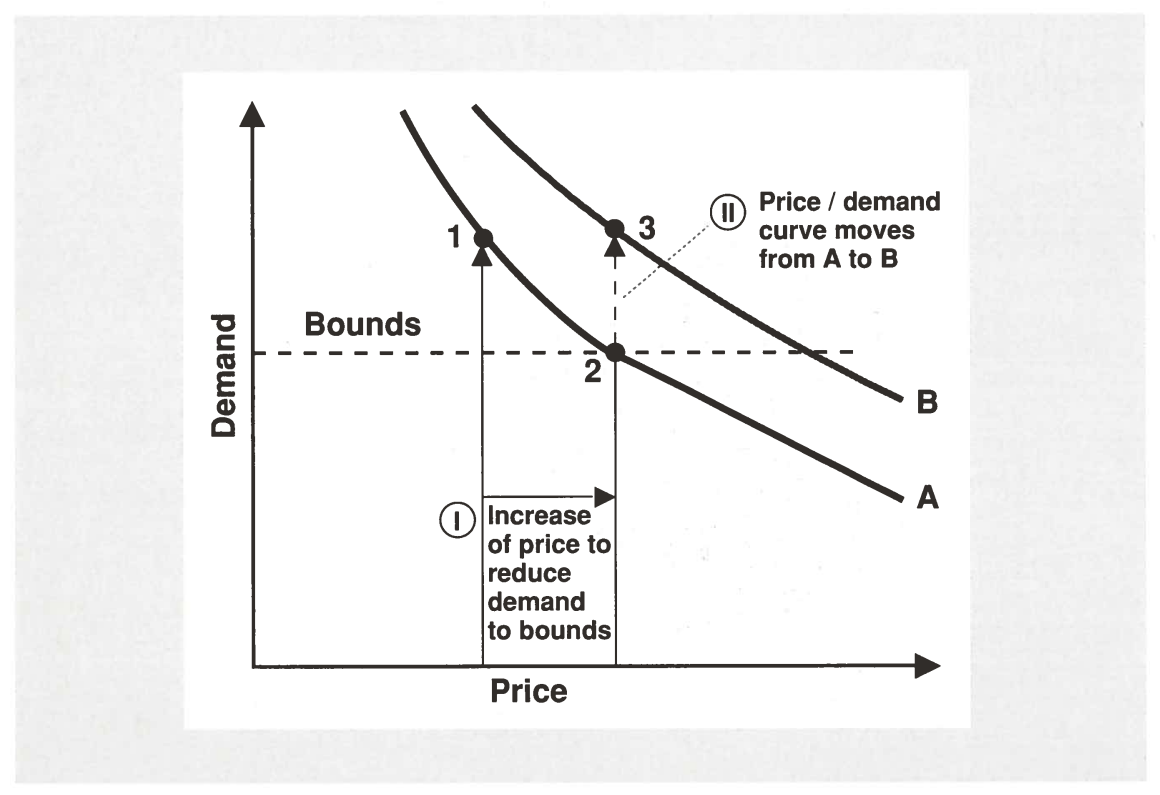

Figure 1. The problem of energy taxation.

Curve A relates energy demand to energy price. If the present demand (point 1 ) is to be reduced to the defined energy bounds (point 2 ), the energy price has to be changed by a well-defined increment. Yet, on a longer time-scale the "economic" structure may shift the price/demand curve to a new position (curve B) which again rises energy demand above the energy bounds (point 3). A new adjustment of the price becomes necessary. At the end we may be confronted simultaneously with a high energy price and a large rate of energy degradation.

Thesis 5: The essential point of the concept of "energy bounds" is not primarily where, when, and at what level the limit is chosen but the simple fact that society agrees to such a limit.

For all the highly committed scientists and politicians who have spent their whole lives trying to convince the society that our present energy needs should be significantly reduced, the idea of "energy bounds" may sound rather vague. Of course, most of us agree that we should not only stabilize, but lower our energy needs. However, we are aware of this necessity since quite some time, and nevertheless the energy demand is still growing. In this respect the goal of energy bounds is rather a first step, a step which may be less spectacular than other programs but more effective, in the long run. Obviously, if a society can cope with a constant energy level, it is only a small step to also reduce its demand, a step which I believe might be taken by the economic system without any further regulations.

\section{Conclusion and Outlook}

Sustainability is an important, but often unrealistic goal, at least for the near future. The concept of constant safe practice assesses human activities according to their inherent prejudices and their flexibility with respect to adjustment. Applied to the problem of energy it means that the main question of a safe energy practice is not primarily "how to use" but "how much to use". And this, by the way, ultimately applies to the use of all natural goods (air, water, land, minerals).

Obviously, the concept of absolute bounds, even if it were accepted by society, does not render obsolete all the ingenious efforts to find less damaging ways of energy supply and the production of consumer goods. However, in the long run it would give the more adequate signal to society than the discussion on "good" and "bad" ways to supply energy and goods. We would slowly learn to act according to the fact (verbally accepted since long ago) that the capacity of "spaceship earth" is limited in much the same way like the available land of a country like Switzerland is finite. Fortunately, most countries have learnt the lesson that the time is over when land supply could be enforced by wars. The 


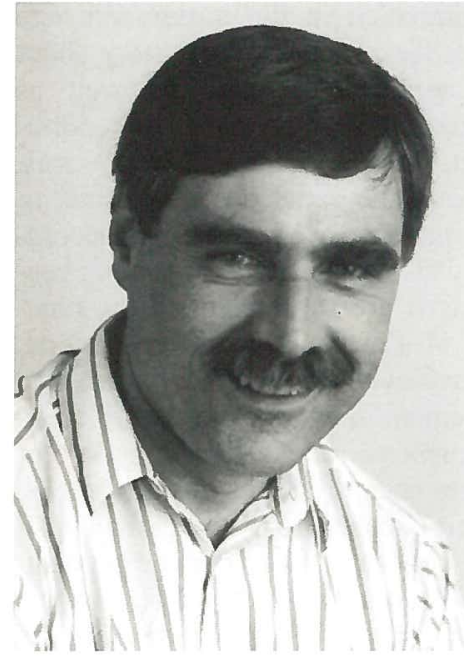

Dieter Imboden: Geboren 1943 in Zürich überlebte mit 10 Jahren beim Umzug nach Basel ohne Schaden seinen ersten Kulturschock. Studium der Theoretischen Physik an der Freien Universität Berlin und an der Universität Basel. Promotion 1971 an der ETH Zürich.

Entwickelte sich seit 1971 an der Eidgenössischen Anstalt für Wasserversorgung, Abwasserreinigung und Gewässerschutz (EAWAG) zunehmend zum Seephysiker und Umweltphysiker, gefördert durch Gastaufenthalte an der Scripps Institution of Oceanography in San Diego, California, der University of Washington in Seattle und am Massachusetts Institute of Technology (MIT). 1986 Leiter der Projektgruppe für den Aufbau eines Umwelt-Studienganges an der ETH Zürich, seit 1988 ordentlicher Professor für Umweltphysik und seit 1992 Vorsteher von Abteilung und Departement für Umweltnaturwissenschaften der ETH.

Arbeitsschwerpunkte: Physik von Gewässern,

Seesanierung, globale Umweltprobleme, Klima und Energie.

last years of our history cast some doubts on whether this lesson has been accepted with respect to the supply of energy, as well.

Many questions remain open. I can clearly hear them in my mind, asked by economists, politicians, and others. For instance: How do we check on the bounds? Do we need a super energy

administration? How do we deal with indirect energy fluxes, hidden in the energy content of materials (as aluminium or concrete)? I am neither the specialist to answer those questions, nor do we need these answers just now. Answers can be found if we want them, like answers have been found for similar problems. Sooner or later our energy policy asks for far-reaching decisions. At the present stage of the discussion we should concentrate on the important issues, not on the operational details. I believe that the choice between energy taxation and alternative strategies, such as the concept of energy bounds, belongs to that category. GAIA could help promoting this discussion.

\section{Literature}

[1] World Resources 1992/93, World Resources Institute, New York (1992).

[2] E.U. von Weizsäcker: Erdpolitik Okologische Realpolitik an der Schwelle zum Jahrhundert der Umwelt, 3. aktualisierte Auflage (nach dem Erdgipfel von Rio de Janeiro), Wissenschaftliche Buchgesellschaft, Darmstadt (1992), p. 223-228; see also E.U. von Weizsäcker, C. von Weizsäcker:

"How to Live with Errors - On the Evolutionary Power of Errors", World Futures 23/3 (1987) 225-235.

[3] R. Rechsteiner: "Sind hohe Energiepreise volkswirtschaftlich ungesund?", GAIA 2 (1993) 310-327.

[4] D.M. Imboden, C.C. Jaeger,

U. Müller-Herold: "Projekt Energieschranke", GAIA 1 (1992) 128. received: August 28, 1993)

As an alternative, solar energy, either exploited by photovoltaic techniques or thermally, could supplement or substitute for other energy resources.

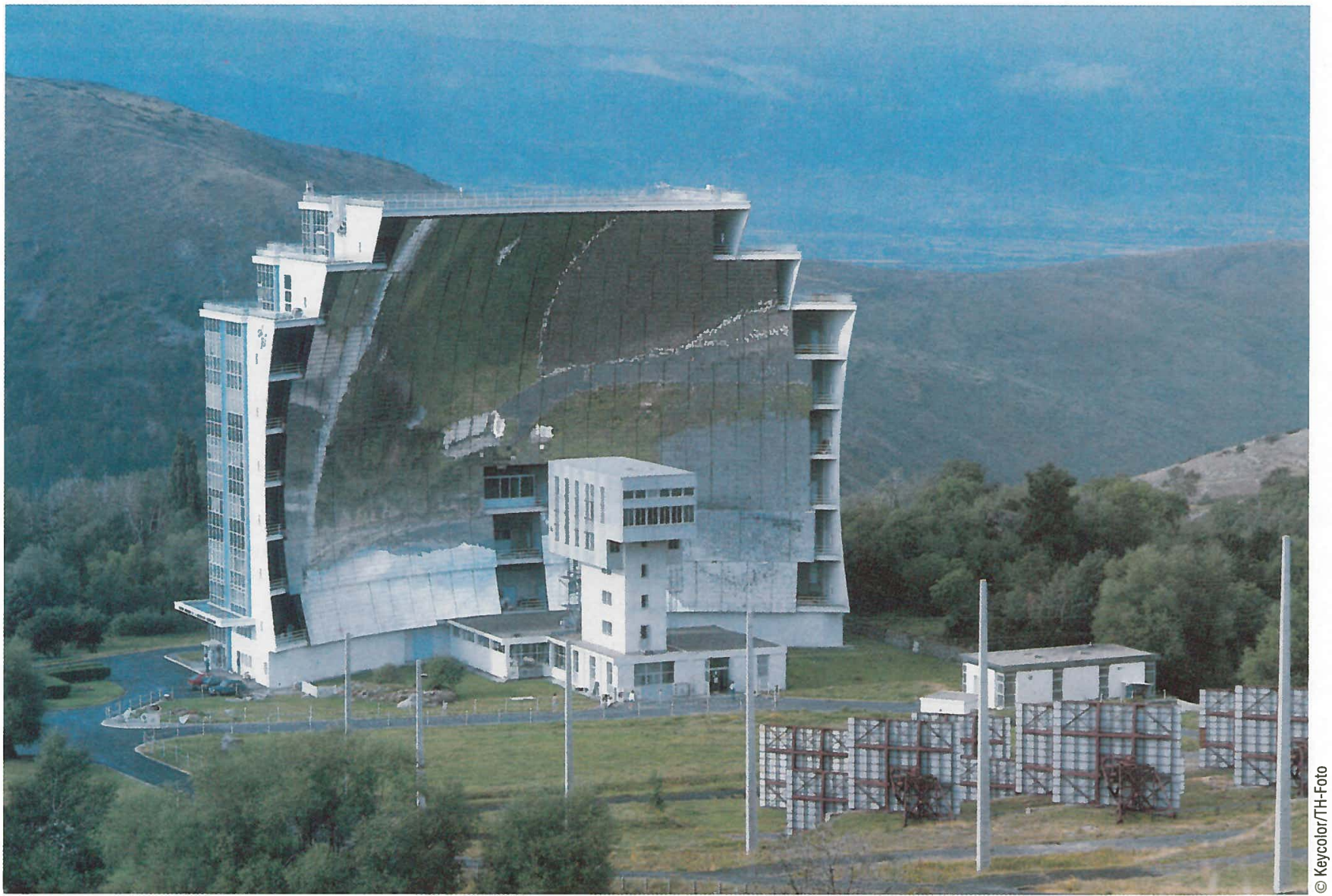

